\title{
Controlled-release oxycodone and naloxone in the treatment of chronic low back pain: A placebo-controlled, randomized study
}

\author{
C Cloutier $M D^{1}$, J Taliano MD², W O'Mahony MD³ ${ }^{3}$ M Csanadi $M D^{4}$, G Cohen $M D^{5}$, I Sutton $M D^{6}$, \\ D Sinclair $M D^{7}, M$ Awde $M D^{8}$, S Henein $M D^{9}$, L Robinson $M D^{10}$, J Eisenhoffer $M D M{ }^{2}{ }^{11}$, \\ PS Piraino $\mathrm{PhD}^{11}$, Z Harsanyi MBA PStat ${ }^{11}$ KJ Michalko PharmD ${ }^{11}$
}

\begin{abstract}
C Cloutier, J Taliano, W O'Mahoney, et al. Controlled-release oxycodone and naloxone in the treatment of chronic low back pain: A placebo-controlled, randomized study. Pain Res Manag 2013;18(2):75-82.
\end{abstract}

BACKGROUND: For Canadian regulatory purposes, an analgesic study was required to complement previously completed, pivotal studies on bowel effects and analgesia associated with controlled-release (CR) oxycodone/CR naloxone.

OBJECTIVES: To compare the analgesic efficacy and safety of $\mathrm{CR}$ oxycodone/CR naloxone versus placebo in patients with chronic low back pain.

METHODS: Patients requiring opioid therapy underwent a two- to sevenday opioid washout before being randomly assigned to receive either $10 \mathrm{mg} / 5 \mathrm{mg}$ CR oxycodone/CR naloxone or placebo every $12 \mathrm{~h}$, titrated weekly according to efficacy and tolerability to $20 \mathrm{mg} / 10 \mathrm{mg}, 30 \mathrm{mg} / 15 \mathrm{mg}$ or $40 \mathrm{mg} / 20 \mathrm{mg}$ every $12 \mathrm{~h}$. After four weeks, patients crossed over to the alternative treatment for an additional four weeks. Acetaminophen/ codeine ( $300 \mathrm{mg} / 30 \mathrm{mg}$ every $4 \mathrm{~h}$ to $6 \mathrm{~h}$ as needed) was provided as rescue medication.

RESULTS: Of the 83 randomized patients, 54 (65\%) comprised the per-protocol population. According to per-protocol analysis, $\mathrm{CR}$ oxycodone/CR naloxone resulted in significantly lower mean $( \pm \mathrm{SD})$ pain scores measured on a visual analogue scale $(48.6 \pm 23.1 \mathrm{~mm}$ versus $55.9 \pm 25.4 \mathrm{~mm} ; \mathrm{P}=0.0296)$ and five-point ordinal pain intensity scores $(2.1 \pm 0.8$ versus $2.4 \pm 0.9 ; \mathrm{P}=0.0415)$ compared with placebo. After the double-blinded phase, patients and investigators both preferred CR oxycodone/CR naloxone over placebo. These outcomes continued in the $79 \%$ of patients who chose to continue receiving $\mathrm{CR}$ oxycodone/CR naloxone in a six-month, open-label evaluation.

CONCLUSIONS: In patients complying with treatment as per protocol, $\mathrm{CR}$ oxycodone/CR naloxone was effective for the management of chronic low back pain of moderate or severe intensity.

Key Words: Controlled-release; Low back pain; Naloxone; Oxycodone

\section{L'oxycodone et la naloxone à libération contrôlée pour traiter les douleurs lombaires aiguës : une analyse aléatoire contrôlée contre placebo}

\begin{abstract}
HISTORIQUE : Pour respecter la réglementation canadienne, il fallait procéder à une étude analgésique pour compléter des études pivots déjà terminées sur les effets intestinaux et l'analgésie de l'association d'oxycodone à libération contrôlée (LC) et de naloxone à LC.
\end{abstract}

OBJECTIFS : Comparer l'efficacité et l'innocuité analgésiques d'une association d'oxycodone à $\mathrm{LC}$ et de naloxone à $\mathrm{LC}$ et celles d'un placebo chez les patients ayant des douleurs lombaires chroniques.

MÉTHODOLOGIE : Les patients qui avaient besoin d'une thérapie aux opioïdes ont subi une période d'élimination des opioïdes de deux à sept jours avant d'être répartis au hasard pour recevoir une association de $10 \mathrm{mg} / 5 \mathrm{mg}$ d'oxycodone à LC et de naloxone à LC ou un placebo toutes les 12 heures, titrés chaque semaine selon l'efficacité et la tolérabilité à $20 \mathrm{mg} / 10 \mathrm{mg}, 30 \mathrm{mg} / 15 \mathrm{mg}$ ou $40 \mathrm{mg} / 20 \mathrm{mg}$ toutes les 12 heures. Au bout de quatre semaines, les patients sont passés au deuxième traitement pendant quatre semaines supplémentaires. Une association d'acétaminophène et de codéine $(300 \mathrm{mg} / 30 \mathrm{mg}$ toutes les quatre heures à six heures, au besoin) était fournie comme médicament de secours.

RÉSULTATS : Sur les 83 patients choisis au hasard, 54 (65\%) formaient la population conforme au protocole. D'après l'analyse conforme au protocole, l'association d'oxycodone à LC et de naloxone à LC favorisait des indices considérablement plus bas qu'un placebo sur l'échelle analogique visuelle $(48,6 \pm 23,1 \mathrm{~mm}$ par rapport à $55,9 \pm 25,4 \mathrm{~mm} ; \mathrm{P}=0,0296)$ et selon les indices ordinaux d'intensité de la douleur en cinq points $(2,1 \pm 0,8$ par rapport à $2,4 \pm 0,9 ; \mathrm{P}=0,0415)$. Après la phase à double insu, les patients et les chercheurs ont tous deux préféré l'association d'oxycodone à LC et de naloxone à LC au placebo. Ces résultats se sont maintenus chez $79 \%$ des patients qui ont choisi de continuer à recevoir une association d'oxydocone à LC et de naloxone à LC dans une évaluation ouverte de six mois. CONCLUSIONS : Chez les patients qui respectent le traitement conformément au protocole, l'association d'oxycodone à LC et de naloxone à LC était efficace pour prendre en charge les douleurs lombaires chroniques, d'intensité modérée ou de forte intensité.

$A$ pproximately four of five Canadian adults experience at least one Aepisode of back pain during their lifetime (1). Chronic back pain is generally defined as pain lasting longer than three (2) or six (3) months, although the pain may never fully resolve; patients may experience repeated exacerbations, with lifetime recurrences in up to $85 \%$ of individuals (2). Accordingly, the economic consequences of treatment decisions for low back pain are substantial $(4,5)$. While the evidence to support many of the treatments used for low back pain varies in quality (6-8), a recurring premise in consensus norms for management is a multidisciplinary approach that considers pharmacological and nonpharmacological therapies $(9,10)$.

Evidence-based clinical practice guidelines for the use of opioids in chronic noncancer pain have recently been published by the American
College of Physicians and the American Pain Society (11). The National Opioid Use Guideline Group, in collaboration with most provincial Colleges of Physicians and Surgeons, have issued a Canadian opioid guideline to aid medical practice for chronic noncancer pain in adults (12).

Controlled release (CR) oxycodone/CR naloxone (Targin, Purdue Pharma, Canada) is a formulation of CR oxycodone and CR naloxone in a 2:1 ratio. The oxycodone component is indicated for the relief of pain, and the naloxone component is indicated for the relief of opioid-induced constipation (OIC) (13). The combination of oral CR oxycodone and CR naloxone provides systemically available oxycodone to address pain control, while the naloxone component provides opioid antagonist effects locally in the gut, preventing activation of the $\mu$-receptor in the

${ }^{1}$ Centre hospitalier universitaire de Sherbrooke-Hopital Fleurimont, Centre de recherché clinique pièce 2820, Sherbrooke, Quebec; ${ }^{2}$ Family Practice,

St Catharines; ${ }^{3}$ Corunna Medical Research Centre, Corunna; ${ }^{4}$ Fort Erie Group Family Practice, Fort Erie; ${ }^{5}$ Brittania Medical Centre, Mississauga,

Ontario; ${ }^{6}$ Health Sciences Centre, Winnipeg, Manitoba; ${ }^{7}$ Family Practice, Aylmer; ${ }^{8}$ Family Practice, London; ${ }^{9}$ Family Practice SKDS Research

Inc, Newmarket; ${ }^{10}$ Optimal Physiotherapy Clinic, Ottawa, Ontario; ${ }^{11}$ Department of Scientific Affairs, Purdue Pharma, Pickering, Ontario

Correspondence and reprints: Mr Z Harsanyi, Purdue Pharma, Department of Scientific Affairs, 575 Granite Court, Pickering, Ontario

L1W 3W8. Telephone 905-420-6400, fax 905-420-2503, e-mail zoltan.harsanyi@purdue.ca 
submucosal and mesenteric plexuses. Activation of these receptors by oxycodone decreases gastric emptying and intestinal peristalsis, reduces the secretion of digestive enzymes and increases fluid absorption. This can lead to nausea, vomiting, loss of appetite and, in the colon, the formation of hard, dry stools and constipation. The presence of naloxone at the gut receptors reduces these effects of oxycodone. In addition, oral naloxone has been demonstrated to have a very low $(<3 \%)$ systemic bioavailability due to first-pass metabolism by the liver. The major product is naloxone glucuronide, an inactive form of naloxone (14).

Double-blinded studies of CR oxycodone/CR naloxone in patients with noncancer pain demonstrated a level of pain relief comparable with that provided by CR oxycodone (OxyContin, Purdue Pharma, Canada) as well as reduced OIC (14-16). Open-label extension studies demonstrated the long-term efficacy and tolerability of fixed combination CR oxycodone/CR naloxone over 52 weeks, with clinically relevant improvements in OIC (17). The results from a large $(n=7836)$, four-week, observational study were consistent with the findings of earlier pivotal clinical trials for analgesia and bowel outcomes (18).

\section{METHODS}

To address Canadian regulatory requirements, an additional analgesic study involving patients with chronic noncancer pain was required. The present trial complements three previously completed, pivotal studies on the safety and efficacy of CR oxycodone/CR naloxone (14-16). Thus, the purpose of the present study was to compare the clinical efficacy and safety of CR oxycodone/CR naloxone with placebo in a randomized, double-blinded, crossover titration-to-effect study in patients with chronic low back pain who had previously not responded adequately to nonopioid therapy and required the use of opioids to control their pain.

\section{Patients}

Adult ( $>18$ years of age) men and nonpregnant (negative pregnancy test), non-nursing women with low back pain of moderate or greater intensity (as assessed by the investigator and the patient using a 5 -point ordinal scale: $0=$ none; $1=$ mild; $2=$ moderate; $3=$ severe; 4 = excruciating) for the previous three months or longer were enrolled in the present study. Patients currently taking opioids or patients who had not previously responded to nonopioid therapy and now required opioids to control their pain were randomized following a two- to seven-day washout from all prestudy opioid analgesics. Patients who were receiving nonopioid analgesics (nonsteroidal antiinflammatory drugs or muscle relaxants) that were stably dosed for two weeks and antidepressants or anticonvulsants that were stably dosed for eight weeks were permitted to continue these medications, provided the doses remained unchanged throughout the study.

Research ethics boards at the 10 participating centres approved the protocol and informed consent, and each patient provided written informed consent before participating in the study. The present study was registered with the International Standard Randomized Controlled Trial Number Registry (ISRCTN \#35931095).

Patients were excluded if they had recently undergone or were to commence any treatments that may have involved the use of preoperative or postoperative analgesics or anesthetics, or that were likely to change their pain during the study period, such as physiotherapy, corticosteroid injections or surgical procedures; required more than 12 tablets of $300 \mathrm{mg} / 30 \mathrm{mg}$ acetaminophen plus codeine; had pain that was expected to be refractory to continuous opioid therapy; had a true allergy or dose-limiting intolerance to acetaminophen, oxycodone, naloxone or any other opioid; had a significant source of pain unrelated to their low back pain that could obscure the assessment of efficacy; had liver enzyme levels (alanine aminotransferase, aspartate aminotransferase or alkaline phosphatase) higher than two times the upper limit of normal or compromised kidney function (serum creatinine level $>20 \mu \mathrm{mol} / \mathrm{L}$ ); had a corrected QT interval >450 ms at baseline; had known severe organ dysfunction or other conditions that, in the opinion of the investigator, adversely affected patient safety or obscured the assessment of efficacy; or had chronic obstructive pulmonary disease, severe asthma, cor pulmonale or heart failure. The present study also excluded patients who were receiving pharmacotherapy that may act as a central nervous system depressant or patients with any other disease or condition that may increase the risk of central nervous system and/or respiratory depression; patients with active peptic ulcer disease, active inflammatory disease of the gastrointestinal tract, or any disease or condition which may affect the absorption of a controlled-release opioid; patients who were known or suspected to have psychological dependence on narcotic analgesics, other psychoactive drugs or excessive consumption of alcohol; patients with a major psychiatric disorder such as major depression or psychotic disease; patients with idiopathic or psychogenic pain in which nonorganic factors were considered to be predominant; or patients who were currently involved in any litigation that was related to their pain, injury and/or disability.

\section{Medication and study design}

Eligible patients underwent a two- to seven-day washout of previous opioid analgesics and stimulant laxatives to establish baseline pain and bowel function. Patients who experienced at least moderate pain (score of 2 on a 5-point scale) after the washout period were eligible to continue in the study. Patients were provided with acetaminophen plus codeine $300 \mathrm{mg} / 30 \mathrm{mg}$ tablets to take for unrelieved pain (one to two tablets every $4 \mathrm{~h}$ as needed) and $8.6 \mathrm{mg}$ senna/docusate sodium tablets (Senokot•S, Purdue Pharma, USA) for constipation (maximum four tablets twice per day) during the washout period.

After the washout period, patients were randomly assigned to receive either $\mathrm{CR}$ oxycodone/CR naloxone or placebo at an initial dose of $10 \mathrm{mg} / 5 \mathrm{mg}$ every $12 \mathrm{~h}$. A computer-generated random allocation listing of patient numbers was generated by the biostatistician and patients entering the study were centrally allocated to the associated treatment condition. Blinding was achieved using the double dummy technique. The patients, investigator and all clinical research staff were blinded. Patients were titrated at weekly clinic visits according to pain control and side effects to $20 \mathrm{mg} / 10 \mathrm{mg}, 30 \mathrm{mg} / 15 \mathrm{mg}$ or a maximum of $40 \mathrm{mg} / 20 \mathrm{mg}$ every $12 \mathrm{~h}$. After four weeks of treatment in the first phase, patients again received the initial dose of $10 \mathrm{mg} / 5 \mathrm{mg}$ $\mathrm{CR}$ oxycodone/CR naloxone or placebo every $12 \mathrm{~h}$, and were titrated as in the first phase. Patients were provided with acetaminophen plus codeine $300 \mathrm{mg} / 30 \mathrm{mg}$ to be taken every $4 \mathrm{~h}$ to $6 \mathrm{~h}$ as required for rescue analgesia in both phases. If a patient experienced dose-limiting side effects or attained complete pain relief, investigators maintained the study drug at the existing dose. Patients were provided with senna/ docusate sodium tablets to treat constipation as required. Investigators were requested to evaluate patients for whether they had neuropathic, nociceptive or both sources of pain under study and whether the patient was expected to respond to opioid therapy.

Patients who successfully completed both phases of the doubleblinded study were eligible to receive CR oxycodone/CR naloxone for a period of six months in an open-label extension, with the investigator's concurrence.

\section{Study evaluations}

Analgesic efficacy was assessed using a 5-point categorical scale for pain intensity $(0=$ none; $1=$ mild; $2=$ moderate; $3=$ severe; 4 = excruciating) and a $100 \mathrm{~mm}$ visual analogue scale (VAS) twice daily in the patient diary at 08:00 and 20:00. Patients also recorded rescue medication use, rescue laxative use, stool frequency (date and time of each bowel movement) and stool consistency (Bristol Stool Form Scale) in their diaries.

At baseline, crossover and end of study, the impact of pain on sleep (since the last evaluation) was assessed using the Pain and Sleep Questionnaire (PSQ) (19-24). Pain and sleep (since the last evaluation) were assessed with a $100 \mathrm{~mm}$ VAS (anchors never to always): 'How often have you needed pain medication to fall asleep?'; 'How often have you had trouble falling asleep because of pain?'; 'How often have you needed sleeping medication to help you fall asleep?; 'How often have you been awakened by pain during the night?'; 'How often have you been awakened by pain in the morning?'; 'If you are sleeping with a partner, 


\begin{tabular}{lcc}
\hline & CR oxycodone/CR naloxone & Placebo \\
\hline Medication dose every $12 \mathrm{~h}, \mathrm{mg}$ & $36.5 \pm 7.3 / 18.2 \pm 3.7$ & $38.1 \pm 5.5 / 19.1 \pm 2.8$ \\
Rescue dose, number of acetaminophen/codeine & $2.6 \pm 3.1(780 / 78)$ & 0.1050 \\
$300 \mathrm{mg} / 30 \mathrm{mg}$ tablets/day (total administered acetaminophen/codeine, mg) & & $0.3 \pm 3.5(1290 / 129)$ \\
Treatment effectiveness* & & 0.0003 \\
Patient & $1.4 \pm 1.0$ & $0.9 \pm 1.0$ \\
Investigator & $1.4 \pm 1.0$ & $1.0 \pm 1.0$ \\
Treatment preference, \% & 56 & 0.0216 \\
Patient (20\% no preference) & 57 & 0.0258 \\
Investigator (15\% no preference) & & 28 \\
Global Impression of Change scores ${ }^{\dagger}$ & $3.2 \pm 1.4$ & 0.0127 \\
Patient & $3.1 \pm 1.4$ & 3.0218 \\
Investigator & & \\
\hline
\end{tabular}

Data presented as mean $\pm S D$ unless otherwise indicated. ${ }^{*} 4$-point scale: $0=$ not effective; $1=$ slightly effective; $2=$ moderately effective; $3=$ highly effective; ${ }^{\dagger} 7$-point scale: 1 = very much improved to 7 = very much worse

how often was your partner awakened from his/her sleep?'. The duration and quality of sleep was assessed by asking the patients (anchors very poor to excellent): 'On average, how many hours of sleep have you been getting each night?' and 'Overall, how would you rate the quality of your sleep?'. Items 1 through 5 were summed to derive an overall score.

Patients were asked to rate their pain-related disability at baseline using the Pain Disability Index (PDI) questionnaire at crossover and end of study $(25,19)$. The PDI consists of seven disability subscales, each representing a different area of everyday functioning: family/ home responsibilities; recreation; social activity; occupation; sexual behaviour; self-care; and life support activity. Each scale is graded from zero to 10 , zero indicating no disability and 10 indicating total disability. The first five disability subscales address discretionary activities and the remaining two address obligatory activities (26,27). An overall disability score is determined by summing the numerical ratings of the seven disability scales (range zero to 70).

At baseline, crossover and end of study, the Quebec Back Pain Disability questionnaire, which consists of 20 items rated on a 5-point categorical scale $(0=$ not difficult at all; $1=$ minimally difficult; 2 = somewhat difficult; 3 = fairly difficult; 4 = very difficult; 5 = unable to do) was administered (28).

At baseline and at the weekly clinic visits, patients were asked to complete the Bowel Function Index (BFI) (29). The BFI consists of three items scored on a 100-point numerical analogue scale: difficulty of bowel movement $(0=$ easy or no difficulty; $100=$ severe difficulty); feeling of incomplete bowel evacuation $(0=$ not at all; $100=$ very strong $)$; and judgement of constipation $(0=$ not at all; $100=$ very strong) over the past week.

At baseline, crossover and end of study visits, the general health status outcome measure (the Short Form 36 [SF-36] health survey), was administered $(30,31)$.

Effectiveness of Treatment $(19,20,32)$ and Global Impression of Change (GIC) (33) were assessed by the patient and the investigator at crossover and end of study. Effectiveness of treatment was assessed using a 4-point categorical scale to describe the effectiveness of the analgesic treatment based on the degree of pain relief over the past seven days (not effective, slightly effective, moderately effective, highly effective).

Overall treatment preference was assessed by the patient and the investigator at the end of the study before unblinding the treatment allocation (Table 1 ) by asking, "Which treatment period did you prefer? The initial period of the study (phase I); the second period of the study (phase II); or no preference.' For GIC, a 7-point ordinal scale was used $(1=$ very much improved; $2=$ much improved; $3=$ minimally improved; $4=$ no change; $5=$ minimally worse; $6=$ much worse; 7 = very much worse).

A modified version of the Subjective Opioid Withdrawal Scale (SOWS) $(34,35)$ was used at baseline, at visit 7 (one week after crossover) and one week after termination of the study to probe for symptoms potentially related to opioid withdrawal during the doubleblinded phase of the study. The scale consisted of 22 symptoms, and patients were asked to rate each symptom as to how they felt over the past week $(0=$ not at all; $1=$ a little; $2=$ moderately; $3=$ quite a bit; 4 = extremely). Fifteen items were taken from the original SOWS (item 16, 'I feel like shooting up today', was omitted as not being relevant to the target population). An additional seven items that have been reported in association with opioid withdrawal in pain patients were also included: 'My sleeping habits have changed'; 'I had to sneeze'; 'I had diarrhea'; 'I felt weak'; 'I felt my heart beating faster'; 'I had an unexplained fever'; and 'I did not feel like eating'. The mean of all 22 ratings was then calculated.

The occurrence and severity $(0=$ none; $1=$ mild; $2=$ moderate; 3 = severe) of any adverse events were assessed at each clinic visit, using a nondirected adverse events questionnaire. Patients were asked to describe any new adverse events or changes in severity of events previously recorded.

Every attempt to adequately treat unacceptable side effects was made, including adjusting the study medication dose. The patient was withdrawn from the study and alternative analgesic treatment was initiated if side effects remained unacceptable. Patients with liver function test values (aspartate aminotransferase or alanine aminotransferase) that were three times the upper limit of normal were discontinued from the study and alternative treatment was initiated. Patients whose pain was not adequately controlled with the study medication and patients who expressed a desire to terminate their participation in the study for any reason were also withdrawn from the study and treated with alternative conventional treatment.

\section{Statistical methods}

Statistical methods were determined before study initiation. Based on variance estimates from previous studies, a difference of $10 \mathrm{~mm}$ on the VAS pain scale was deemed to be detectable with a minimum of 52 evaluable patients, assuming type I and type II error rates of 0.05 and 0.20 , respectively, for testing a two-tailed hypothesis. The per-protocol population was defined as all patients who completed at least two weeks in each phase without any major protocol violations. The intent-totreat (ITT) population included all patients who ingested at least one study medication dose and had at least one postrandomization data point. Adverse events were analyzed for all patients randomized.

The primary efficacy end-points were the VAS and 5-point ordinal pain scores from the patient daily diary averaged over the final week of each treatment for the per-protocol population. Analyses based on the ITT population were prespecified as subordinate because the purpose of the present trial was to test the safety and effectiveness of $\mathrm{CR}$ oxycodone/CR naloxone when taken as prescribed and in accordance with the protocol, to test an explanatory hypothesis on the effectiveness of this product. A general linear ANOVA model was 


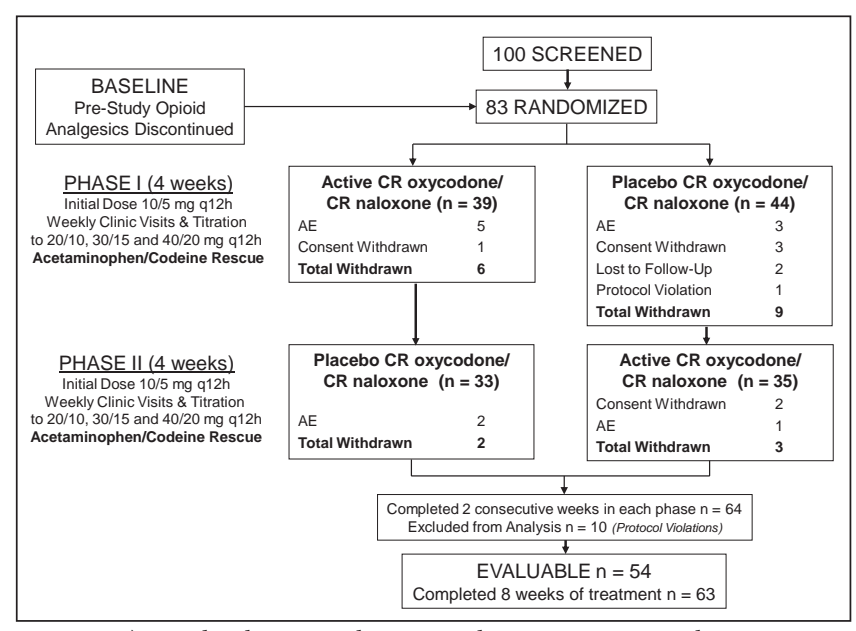

Figure 1) Study design and patient disposition. AE Adverse events; CR Controlled release; $q 12 \mathrm{~h}$ Every $12 \mathrm{~h}$

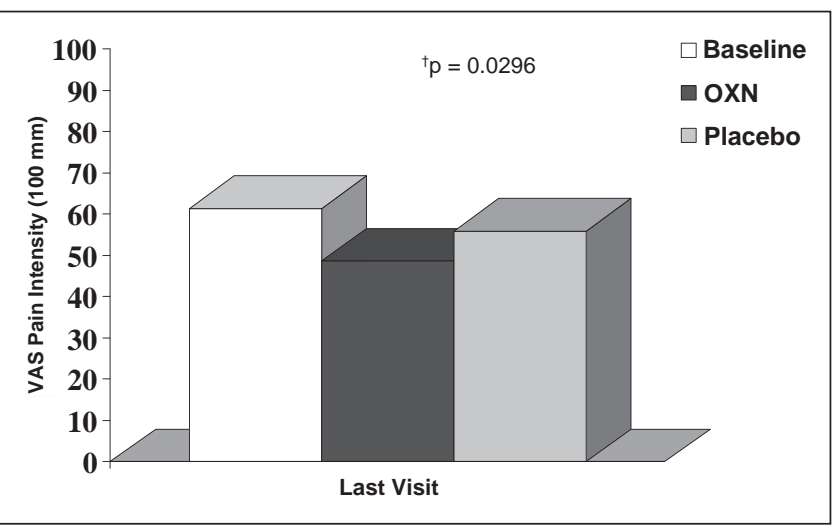

Figure 2) Pain intensity during the final week of treatment. The change from baseline for the controlled release (CR) oxycodone/CR naloxone (OXN) group was $12.3 \pm 21.8 \mathrm{~mm}(P=0.0002)$ compared with $5.7 \pm 23.1 \mathrm{~mm}$ for the placebo group $(P=0.0821)$, measured on a visual analogue scale (VAS), and the change in ordinal pain scores was $0.4 \pm 0.7$ for the OXN group $(P=0.0004)$ and $0.2 \pm 0.8$ for the placebo group $(P=0.1607)$, respectively

used for analysis of most efficacy parameters, with terms for patient, phase, sequence and patient within sequence (Type III sum of squares, PROC GLM analysis; SAS version 9.1.3, SAS Institute Inc, United States). The effect of first-order carryover was assessed by testing for the significance of the sequence effect using the within-patient variance as the error term. In the event of detection of a statistically significant carryover effect, analysis would be limited to phase I data. Treatment preference rates, as rated by investigator and patient separately, were compared using Prescott's test (36), which takes into account the 'no preference' responses. Statistical significance was defined as $\mathrm{P}<0.05$ for a two-tailed hypothesis. Because there were two primary end-points, however, significance in both was required, no adjustment was necessary for determining the type 1 error rate.

\section{RESULTS}

One hundred patients were screened and 83 patients were included in the present study (Figure 1). Twenty patients discontinued the study, with nine dropping out during active treatment and 11 during placebo treatment. The reasons for dropout were due to adverse events $(n=11)$, consent withdrawn $(n=6)$, protocol violation $(n=1)$ or lost to follow-up $(n=2)$. Of those discontinuing the study due to adverse events, six were during active treatment and five were during placebo administration. Withdrawal of consent was equally split, with three in each phase. Ten patients were disqualified from per-protocol analysis due to initiation or adjustment of antidepressant doses during the study $(n=5)$, noncompliance with study medication dosing $(n=2)$, use of
TABLE 2

Pain and Sleep Questionnaire scores during the final week of treatment (per-protocol population $n=54$ )

\begin{tabular}{|c|c|c|c|c|}
\hline Item & Baseline & $\begin{array}{c}\text { CR } \\
\text { oxycodonel } \\
\text { CR } \\
\text { naloxone }\end{array}$ & Placebo & $\mathbf{P}$ \\
\hline Trouble falling asleep & $64.1 \pm 29.7$ & $40.8 \pm 28.5^{\dagger}$ & $56.2 \pm 30.7$ & $0.0062^{*}$ \\
\hline eeded pain meds to sleep & $59.3 \pm 33.8$ & $42.1 \pm 34.7^{\dagger}$ & $51.1 \pm 35.2$ & .1501 \\
\hline ep & 37.1 & $26.8 \pm$ & 7.4 & 02 \\
\hline wakened by pain at night & $60.4 \pm 29.4$ & $3.0 \pm 32.6^{\dagger}$ & $56.4 \pm 32.3$ & $0.0098^{*}$ \\
\hline wakened by pain I & $63.8 \pm 29.6$ & $47.0 \pm 34.1^{\dagger}$ & $60.3 \pm 29.9$ & $0.0081^{*}$ \\
\hline artn & $44.6 \pm 32.2$ & $35.9 \pm 31.4$ & $45.7 \pm 34.1$ & 0.0588 \\
\hline ou & & & & \\
\hline Quality of sleep & $31.5 \pm 26.7$ & $38.2 \pm 27.4$ & $33.8 \pm 22.5$ & 0.2195 \\
\hline \multicolumn{5}{|c|}{ Overall pain and sleep scores $285.2 \pm 124.5200 .2 \pm 128.2 \quad 257.4 \pm 127.80 .0046^{\star \ddagger}$} \\
\hline \multicolumn{5}{|c|}{$\begin{array}{l}\text { Data presented as mean } \pm S D \text { unless otherwise indicated. There were signifi- } \\
\text { cantly improved scores in three of eight items and overall Pain and Sleep } \\
\text { Questionnaire scores after controlled release }(C R) \text { oxycodone/CR naloxone } \\
\text { treatment compared with placebo }(*) \text {. In addition, statistically significant } \\
\text { improvements from baseline were observed in four of eight items with } C R \\
\text { oxycodone/CR naloxone }\left({ }^{\dagger} P \leq 0.0006\right) \text {, while no statistically significant changes } \\
\text { from baseline were observed after placebo treatment. The decreases from } \\
\text { baseline for the overall Pain and Sleep Questionnaire scores were } 29.6 \% \\
\left({ }^{\ddagger} P<0.0001\right) \text { and } 8.2 \%(P=0.1548) \text { following } C R \text { oxycodone } / C R \text { naloxone and } \\
\text { placebo treatments, respectively. meds Medications }\end{array}$} \\
\hline
\end{tabular}

prestudy anesthetics that were considered likely to change the patient's pain during the study period $(n=2$; paraspinal injections [marcaine $0.5 \%$ solution] are felt within $24 \mathrm{~h}$ and have a duration of approximately four weeks, thereby altering the patient's pain over the course of the study), and reported opioid dependence and abuse during the study $(n=1)$. Fifty-four patients that completed at least two weeks in each phase and met all the criteria for evaluability (Figure 1) were included in the per-protocol analysis ( 27 men, 27 women, mean [ \pm SD] age $50.6 \pm 10.9$ years; $94.4 \%$ were Caucasian, $1.9 \%$ Asian and $3.7 \%$ other). The average duration of low back pain was $13.8 \pm 10.3$ years, with $51 \%$ of the patients reporting not working (unemployed or not attending work). Sixty-nine per cent $(\mathrm{n}=37)$ were assessed as having a neuropathic component to their back pain.

In the ITT population, the majority $(n=75[90.4 \%])$ of the patients were taking opioid analgesics for their chronic low back pain before the trial, while eight patients $(9.6 \%)$ were opioid naive. Twenty patients $(24 \%)$ were taking an oxycodone/acetaminophen combination, 12 patients $(14 \%)$ were taking CR oxycodone and four patients (5\%) a different oxycodone product. Other prestudy treatments included acetylsalicylic acid/ibuprofen/acetaminophen (33.7\%), other nonsteroidal anti-inflammatory drugs (31.3\%), antidepressants/ anticonvulsants (19.3\%), muscle relaxants $(12.0 \%)$, local anesthetic injections $(9.6 \%)$ and other $(7.2 \%)$.

The mean $( \pm$ SD) daily dose of study medication during the final week of each treatment phase was $36.5 \pm 7.3 \mathrm{mg} / 18.2 \pm 3.7 \mathrm{mg}$ every $12 \mathrm{~h}$ in the CR oxycodone/CR naloxone treatment group and $38.1 \pm 5.5 \mathrm{mg} / 19.1 \pm 2.8 \mathrm{mg}$ every $12 \mathrm{~h}$ in the placebo group for the perprotocol population $(\mathrm{P}=0.1050)$ (Table 1$)$.

The mean baseline daily VAS and ordinal pain scores were $61.4 \pm 16.3 \mathrm{~mm}$ and $2.5 \pm 0.6$ for the per-protocol population. In the final week of treatment, mean VAS pain scores decreased to $48.6 \pm 23.1 \mathrm{~mm}$ and $55.9 \pm 25.4 \mathrm{~mm}$ in the CR oxycodone/CR naloxone and placebo groups, respectively. The difference between the treatment groups was statistically significant $(\mathrm{P}=0.0296)$ (Figure 2). Similar results were observed with the ordinal pain scores after the final week of treatment (active versus placebo $2.1 \pm 0.8$ versus $2.4 \pm 0.9$, respectively; $\mathrm{P}=0.0415$ ) There was no indication of a carryover effect for both the per-protocol and ITT populations $(\mathrm{P}=0.6989$ and $\mathrm{P}=0.6179)$.

Overall PSQ scores were significantly improved with CR oxycodone/CR naloxone compared with placebo $(\mathrm{P}=0.0046)$ 
TABLE 3

Pain and Disability Index (PDI) scores during the final week of treatment (per-protocol population $n=54$ )

\begin{tabular}{lcccc}
\hline \multicolumn{4}{c}{ CR oxycodonel } \\
& Baseline & CR naloxone & Placebo & P \\
\hline Family/home responsibility & $6.2 \pm 2.1$ & $5.4 \pm 2.5^{*}$ & $5.6 \pm 2.3^{\dagger}$ & 0.3902 \\
Recreation & $7.1 \pm 2.5$ & $6.2 \pm 2.9^{*}$ & $6.5 \pm 3.0$ & 0.3167 \\
Social activity & $6.2 \pm 2.7$ & $5.4 \pm 2.6^{*}$ & $5.8 \pm 2.9$ & 0.0815 \\
Occupation & $6.9 \pm 2.4$ & $5.9 \pm 3.0^{*}$ & $6.3 \pm 2.9$ & 0.1592 \\
Sexual behaviour & $6.7 \pm 2.7$ & $5.2 \pm 3.2^{*}$ & $5.3 \pm 3.3^{\dagger}$ & 0.5419 \\
Self care & $4.4 \pm 2.7$ & $3.4 \pm 2.9^{*}$ & $4.1 \pm 2.9$ & 0.0500 \\
Life suport & $4.5 \pm 2.8$ & $3.0 \pm 2.8^{*}$ & $4.0 \pm 2.9$ & 0.0190 \\
Total pain and disability & $42.0 \pm 13.2$ & $34.3 \pm 15.6^{\ddagger}$ & $37.5 \pm 15.2^{\S}$ & 0.0511 \\
\multicolumn{1}{l}{ index scores } & & & & \\
\hline
\end{tabular}

Data presented as mean $\pm S D$ unless otherwise indicated. There were statistically significant improvements after controlled release (CR) oxycodone/CR naloxone treatment compared with placebo treatment for two items (self care and life support), and the total PDI scores approached statistical significance between treatments $(P=0.0511)$. There were statistically significant improvements from baseline in all seven subscales following treatment with $C R$ oxycodone/CR naloxone $\left({ }^{*} P<0.0264\right)$ and in only two subscales following placebo treatment $\left({ }^{\top} P \leq 0.0142\right)$. The decreases from baseline for the total $P D I$ scores were $18.7 \%\left({ }^{\ddagger} P=0.0001\right)$ and $10.6 \%\left({ }^{\$} P=0.005\right)$ following $C R$ oxycodone/CR naloxone and placebo treatments, respectively

(Table 2). PDI scores are listed in Table 3 and the overall PDI scores approached statistical significance $(\mathrm{P}=0.0511)$. There were no differences between treatment groups for all of the SF-36 domains and total Quebec Back Pain scores or individual items at the end of the study.

Mean BFI scores did not change during the final week of treatment compared with baseline $(39.3 \pm 33.0)$ for CR oxycodone/CR naloxone or placebo $(33.6 \pm 30.2 ; \mathrm{P}=0.2412$ and $32.4 \pm 29.5 ; \mathrm{P}=0.1586$, respectively), and the difference between treatment groups was not statistically significant $(\mathrm{P}=0.8729)$ (Figure 3$)$.

The mean frequency of bowel evacuation was similar to baseline $(1.0 \pm 0.5 /$ day $)$, with no difference between the treatment groups at the end of the study $(0.9 \pm 0.5$ tablets/day for the CR oxycodone/CR naloxone group and 1.0 \pm 0.6 tablets/day for the placebo group; $\mathrm{P}=0.1152$ ).

Stool consistency, as measured by the Bristol Stool Score, also did not change from baseline $(3.6 \pm 1.1)$ and was similar between treatment groups at the end of the study $(3.7 \pm 1.1$ for the CR oxycodone/ CR naloxone group and $3.6 \pm 1.0$ for the placebo group; $\mathrm{P}=0.8094$ ).

There was no difference in the use of rescue laxatives (senna/ docusate sodium tablets) during the final week of treatment $(0.4 \pm 0.7$ tablets/day for the $C R$ oxycodone/naloxone group and $0.4 \pm 0.8$ for the placebo group; $\mathrm{P}=0.4439$ ).

At baseline, one week after withdrawal of prestudy opioid analgesics, the mean SOWS score was $0.85 \pm 0.59$. One week after the end of each treatment phase, the mean SOWS scores for the $\mathrm{CR}$ oxycodone/CR naloxone and placebo groups were $0.76 \pm 0.60$ and $0.79 \pm 0.60$, respectively $(P=0.5595)$.

Table 4 lists the incidence of the most common adverse events. There were no significant differences between treatment groups in the overall incidence of adverse events $(\mathrm{P}=0.0679)$. Among common adverse events, significantly more somnolence was reported during the active treatment phases $(\mathrm{P}=0.045)$. There were four patients who reported serious adverse events during the trial. Two occurred during placebo treatment (one fracture in association with an accidental fall, and suspected recurrent transient ischemic attacks with weakness, lack of coordination of hands and difficulty speaking) and two occurred during $\mathrm{CR}$ oxycodone/CR naloxone treatment (hospitalization for abdominal cramps, gas, nausea, diarrhea and fever, and for diverticulitis and irritable bowel syndrome) The investigator's assessments in all four cases were "not related to study medication".

The ITT population included 83 patients ( 39 men, 44 women; mean [ \pm SD] age $51.3 \pm 12.5$ years; $91.6 \%$ were Caucasian, $2.4 \%$ Asian and $6.0 \%$ other). Mean daily doses observed in the ITT population

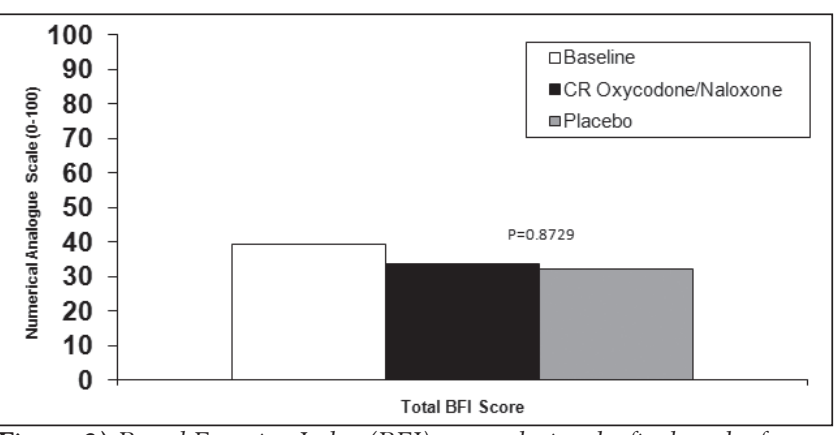

Figure 3) Bowel Function Index (BFI) scores during the final week of treatment in the per-protocol group. CR Controlled release

\section{TABLE 4}

Incidence of most common adverse events*

\begin{tabular}{lccc}
\hline Adverse event & $\begin{array}{c}\text { CR oxycodonel } \\
\text { CR naloxone } \\
\mathbf{n}(\%)\end{array}$ & $\begin{array}{c}\text { Placebo } \\
\mathbf{n}(\%)\end{array}$ & $\mathbf{P}$ \\
\hline Nausea & $9(12.2)$ & $9(11.7)$ & 0.7630 \\
Constipation & $6(8.1)$ & $2(2.6)$ & 0.1025 \\
Diarrhea & $4(5.4)$ & $7(9.1)$ & 0.3173 \\
Fatigue & $4(5.4)$ & $2(2.6)$ & 0.4142 \\
Somnolence & $4(5.4)$ & $0(0)$ & 0.0455 \\
Vomiting & $4(5.4)$ & $3(3.9)$ & 0.6547 \\
Dizziness & $3(4.1)$ & $2(2.6)$ & 1.0000 \\
Dry mouth & $3(4.1)$ & $4(5.2)$ & 0.4142 \\
Upper respiratory tract infection & $3(4.1)$ & $0(0)$ & 0.0833 \\
Abdominal pain & $2(2.7)$ & $5(6.5)$ & 0.4142 \\
Overall & $48(64.9)$ & $40(51.9)$ & 0.0679 \\
\hline
\end{tabular}

${ }^{*}$ Based on 74 patients who received controlled release (CR) oxycodone/ $C R$ naloxone and 77 patients who received placebo. During CR oxycodone/ $C R$ naloxone treatment, 99 events were reported with a mean maximum severity of 1.5 compared with 107 events with a mean maximum severity of 1.6 in the placebo group. $7.2 \%$ and $6.0 \%$ of patients withdrew from the study due to adverse events in the CR oxycodone/CR naloxone and placebo groups, respectively (Figure 1)

(36.5 $\mathrm{mg} / 18.2 \mathrm{mg}$ ) were similar to the per-protocol population (34.2 mg/17.1 mg; P=0.2595), with significantly less rescue medication (acetaminophen/codeine $300 \mathrm{mg} / 30 \mathrm{mg}$ tablets) used in the $\mathrm{CR}$ oxycodone/CR naloxone treatment group compared with the placebo group ( $\mathrm{P}=0.0003$ ) (Table 1$)$. VAS and 5-point ordinal pain intensity scores during the final week of treatment with CR oxycodone/CR naloxone compared with placebo were $52.2 \pm 23.0 \mathrm{~mm}$ versus $57.8 \pm 24.2 \mathrm{~mm}(\mathrm{P}=0.0527)$ and $2.3 \pm 0.8$ versus $2.5 \pm 0.9$ $(\mathrm{P}=0.0862)$, respectively.

Fifty patients were enrolled in the open-label extension, during which they received treatment with CR oxycodone/CR naloxone for up to six months. The mean duration of treatment was $163.5 \pm 41.6$ days, and 40 patients completed a full six months of treatment. The reasons for withdrawal from the open-label study were: adverse events $(n=3)$, insufficient therapeutic effect $(n=2)$, protocol violation $(n=1)$ and other $(n=2)$. There was one patient who underwent less than one day of treatment in open-label (started and stopped on the same day) but was nevertheless included in the analysis, and one patient was lost to follow-up. Only an ITT analysis was applied to the open-label phase.

The mean oxycodone dose per day did not vary greatly from the end of the double period $(36.0 \mathrm{mg} / 18.0 \mathrm{mg} \pm 8.3 \mathrm{mg} / 4.15 \mathrm{mg})$ to the end of open-label period $(35.10 \mathrm{mg} / 17.55 \mathrm{mg} \pm 9.30 \mathrm{mg} / 4.65 \mathrm{mg})$. Ordinal pain scores decreased from $2.5 \pm 0.83$ at the final doubleblinded assessment to $1.8 \pm 0.71$ at the end of the open-label period.

\section{DISCUSSION}

The results of the present randomized, double-blinded, crossover study showed that $\mathrm{CR}$ oxycodone/CR naloxone was significantly more 
effective than placebo in the treatment of chronic low back pain when initiated at a dose of $10 \mathrm{mg} / 5 \mathrm{mg}$ and titrated to effect to a maximum dose of $40 \mathrm{mg} / 20 \mathrm{mg}$ every $12 \mathrm{~h}$. This treatment effect was demonstrated despite a significantly greater use of rescue analgesia in the placebo group.

For both primary assessments of pain intensity (VAS and ordinal), CR oxycodone/CR naloxone produced significantly lower scores than placebo treatment in titrated patients taking study medications as prescribed. The difference in $100 \mathrm{~mm}$ VAS score between CR oxycodone/CR naloxone and placebo was $7.3 \mathrm{~mm}$, and there was a difference of 0.3 on the ordinal scale. Reductions in chronic pain intensity of $10 \%$ to $20 \%$ are considered to reflect minimally important changes (37). The improvement in pain from baseline for CR oxycodone/ CR naloxone was $21 \%$ on the $100 \mathrm{~mm}$ VAS and $16 \%$ on the ordinal scale. The finding that a statistically significant majority of patients and investigators preferred the $\mathrm{CR}$ oxycodone/CR naloxone treatment phase for the management of pain, when asked before unblinding of the treatment allocation, demonstrates that the differences in treatment outcomes between CR oxycodone/CR naloxone and placebo treatments were clinically evident to the patients and investigators. In addition, both patients and investigators rated the effectiveness and GIC of CR oxycodone/CR naloxone as significantly greater than placebo. CR oxycodone/CR naloxone also provided a statistically significant benefit for patients' sleep and improvement in the overall PSQ score compared with placebo, which was accompanied by significant improvements from baseline in three of eight items on the questionnaire for $\mathrm{CR}$ oxycodone/CR naloxone treatment. Sleep disturbance is a common complaint among patients with chronic pain (38) and changes in sleep affect pain reporting (39); therefore, sleep quality is an important goal in pain management.

The corresponding differences in pain scores in the ITT population trended in the direction observed in the per-protocol analysis, with differences of $5.6 \mathrm{~mm}$ and 0.2 relative to placebo on VAS and ordinal pain scores, respectively. However, the differences did not reach statistical significance for VAS $(\mathrm{P}=0.0527)$ or ordinal pain $(\mathrm{P}=0.0862)$ scores. With the study powered for a per-protocol analysis, potential factors for these outcomes include a lack of sufficient within-patient data available from subjects in the ITT analyses.

Due to the ethical concerns that may be associated with placebocontrolled studies, an active opioid rescue medication was used. In the present study, the higher consumption of active rescue medication in the placebo group reached statistical significance, with the placebo group using approximately two additional tablets of codeine/acetaminophen daily compared with the CR oxycodone/ CR naloxone group. The use of an active opioid rescue as a pro re nata regimen in a placebo-controlled study helps patients to cope with placebo therapy. The significantly lower use of opioid rescue medication in the CR oxycodone/CR naloxone group is consistent with the finding of superior analgesia versus placebo. Additionally, and consistent with the observed pain scores, all of the secondary measures trended in the same direction.

Most chronic low back pain is musculoskeletal and mechanically induced and, thus, nociceptive in nature, but many patients may have symptoms consistent with an additional neuropathic component. In the present study, approximately $67 \%$ of the patients were assessed as having a neuropathic component to their pain. Previously, it was believed that opioids were not as effective for neuropathic pain as for nociceptive pain, but based on a growing number of randomized placebo-controlled studies, it is now accepted that opioids, including CR oxycodone, are effective in treating neuropathic pain (19,20,40-42). Approximately $90 \%$ of the patients had previously been treated with an opioid, including $40 \%$ on oxycodone. Analyses did not subdivide patients based on previous use of oxycodone versus those with no recent use. With practice of medicine documents as a guide, the exclusion of populations with a history of substance misuse or severe mental illness was made in the present double-blinded, randomized clinical trial.
There was no statistically significant difference between treatment groups with regard to BFI scores, stool frequency and consistency, or laxative usage, and there were no significant changes from baseline in any of these assessments. There was, however, no enrollment requirement for pre-existing constipation for the present study, and, on average, the study population was not constipated at the outset, as demonstrated by the mean bowel evacuation scores of $1.0 \pm 0.5$ per day. An excessive laxation effect of CR oxycodone/CR naloxone was not observed in treatment groups that were not constipated at the outset. Moreover, before study entry, less than one-half of the patients (42\%) were using singleentity opioids (although $68 \%$ of patients had been using a combination opioid preparation). By the end of the study, patients in the active treatment group were receiving a mean daily dose of approximately $73 \mathrm{mg}$ CR oxycodone (plus approximately $750 \mathrm{mg} / 75 \mathrm{mg}$ per day of acetaminophen plus codeine in the form of rescue medication). Given that CR oxycodone/CR naloxone yields oxycodone plasma levels comparable with $\mathrm{CR}$ oxycodone, it is noteworthy that CR oxycodone/CR naloxone was not associated with a statistically significant change in bowel function. However, the design of the present trial is not suitable to prove that the naloxone component of $\mathrm{CR}$ oxycodone/CR naloxone pre-empted the development of OIC.

The most common reason for withdrawal from the study was adverse events (see Figure 1). The overall rate of withdrawal in the present study was $24 \%$. Five patients in the placebo group and six patients in the CR oxycodone/CR naloxone group dropped out due to adverse events. Overall dropouts were relatively balanced between the treatment groups and therefore not considered to be biasing the primary analysis. This equates to a withdrawal rate due to adverse events in the CR oxycodone/CR naloxone treatment phase of $7.2 \%$.

Although there were two serious adverse events during CR oxycodone/CR naloxone treatment, investigators deemed these to be unrelated to study medication. There were no statistically significant differences in adverse events between CR oxycodone/ $\mathrm{CR}$ naloxone and placebo treatments except for somnolence, which occurred more frequently in patients receiving CR oxycodone/ $\mathrm{CR}$ naloxone. Adverse events, such as asthenia, constipation, dizziness, dry mouth, headache, nausea, pruritus, somnolence, sweating and vomiting, are common for oxycodone-containing products (43). Overall, the rate of adverse events was low, with all adverse events reported by $\leq 12.2 \%$ of patients. The low incidence of adverse events compared with placebo for CR oxycodone/CR naloxone in the present study is consistent with a favourable safety profile.

$\mathrm{CR}$ oxycodone/CR naloxone is unique in containing both an agonist and an antagonist with a low systemic bioavailability; therefore, the question arises as to whether opioid withdrawal effects may be observed during the course of the study. No statistically significant differences were observed between treatments with respect to the symptom listing on a modified SOWS scale, either during the study treatment phases or on discontinuation of CR oxycodone/CR naloxone before crossover to placebo in the double-blinded phase. The purpose of the modified SOWS questionnaire was to provide a structured probe of symptoms commonly associated with the syndrome of opioid withdrawal in patients undergoing pain therapy. In addition, there were no reports of withdrawal symptoms by the investigators at any time during the study. This is consistent with findings in other clinical trials with CR oxycodone/CR naloxone, in which discontinuation of treatment did not result in opioid withdrawal in controlled use for up to three months $(14,16)$.

As noted by Martell et al (44), most published controlled studies of opioids for chronic low back pain are of relatively short duration, providing little evidence regarding the efficacy or safety of long-term opioid treatment (45-48). However, a three-month, double-blinded controlled study demonstrated a statistically significant improvement in pain intensity and pain relief scores with CR oxycodone compared with placebo (49). Similar conclusions were reached in a study of CR oxycodone involving more than 200 patients with chronic noncancer pain for periods of up to three years (50). Approximately equal 
numbers of patients with osteoarthritis, neuropathic pain or low back pain were enrolled. While nearly one-half of the patients required a dose increase in the first three months, further increases thereafter were gradual and minimal, and were associated with stable levels of pain control. Based on observer reports of drug-seeking behaviour, six patients were assessed as having probable drug abuse or dependence, although none met formal diagnostic criteria for substance abuse. Findings of stable pain control and absence of statistically significant dose escalation have also been reported in other studies with CR oxycodone (51) or CR morphine (52) for treatment periods of up to three to 4.5 years and one year, respectively.

The improvements in pain scores observed during the randomized phase of the present study in patients taking the product as prescribed were sustained for the treatment period of up to six months. Moreover, the mean dose of CR oxycodone/CR naloxone at the end of the open-label phase was comparable with the mean dose during the corresponding double-blinded phase. The tolerability of CR oxycodone/CR naloxone was maintained throughout the openlabel phase of the study. In the results of the long-term extension phase of the present study, it was observed that patients stabilized on CR oxycodone/CR naloxone maintained efficacy and tolerability for an extended period of time without dose increases.

The present study was adequately powered to detect a difference between treatments, and the target sample size was consistent with power calculations for crossover study designs (36). In terms of the length of patient exposure to blinded treatment, the randomized portion of the study was eight weeks in duration. An effort was made to keep the enrollment criteria as broad as possible while remaining within clinical practice norms for the use of opioids in suitable patients with chronic low back pain. Enrolled subjects met these criteria, but a skewed distribution of subjects according to race for Caucasians emerged. This is reflective of the catchment populations at the investigational sites.

\section{CONCLUSION}

In patients who had previously been treated with opioids or were scheduled for opioid treatment, on the primary measure of analgesic efficacy, pain control was significantly better in the CR oxycodone/CR naloxone treatment phase compared with the placebo phase in patients adherent to the protocol, including their taking of blinded study medications. Independent of the increased use of rescue medication in the blinded placebo arm, patient and investigator ratings of treatment effectiveness and preference indicated a meaningful therapeutic benefit of $\mathrm{CR}$ oxycodone/CR naloxone. There were no statistically significant differences in reported adverse events in patients receiving active treatment compared with placebo, except for somnolence, which occurred more frequently with $\mathrm{CR}$ oxycodone/CR naloxone. The analgesic response profile from the double-blinded phase of the trial continued over the six-month openlabel phase. CR oxycodone/CR naloxone was effective for analgesic treatment, with an acceptable tolerability profile, in patients with chronic low back pain when initiated at a dose of $10 \mathrm{mg} / 5 \mathrm{mg}$ every $12 \mathrm{~h}$ with rescue medication and titrated on this regimen, as necessary, up to $40 \mathrm{mg} / 20 \mathrm{mg}$ every $12 \mathrm{~h}$.

In patients not constipated at outset, titration to effect with CR oxycodone/CR naloxone in a randomized, double-blinded, crossover trial was not associated with increased constipation or any other deleterious bowel symptoms relative to placebo. The foregoing outcomes are consistent with previously completed, pivotal trials powered for ITT analyses on analgesia (46) and bowel function $(47,48)$. Collectively, these data lay the basis for definitive trials with $\mathrm{CR}$ oxycodone/CR naloxone for the prevention of OIC.

ACKNOWLEDGEMENTS: The present research was supported by a research grant from Purdue Pharma. Trial Registration number: ISRCTN35931095.

\section{REFERENCES}

1. Statistics Canada. Musculoskeletal diseases: Back pain. <www.statcan.gc.ca/pub/82-619-m/2006003/4053542-eng.htm> (Accessed December 9, 2008).

2. Woolf AD, Pfledger B. Burden of major musculoskeletal conditions. Bulletin of the WHO 2003;81:646-56.

3. Thienhaus O, Cole BE. The classification of pain. In: Weiner RS, ed. Pain Management: A Practical Guide for Clinicians, 6th edn. Boca Raton: CRC Press, 2002:29.

4. Asche CV, Kirkness CS, McAdam-Marx C, Fritz JM. The societal costs of low back pain: Data published between 2001 and 2007. J Pain Palliat Care Pharmacother 2007;21:25-33.

5. Dagenais S, Caro J, Haldeman S. A systematic review of low back pain cost of illness studies in the United States and internationally. Spine J 2008;8:8-20.

6. Jonsson E. Introductory comments. In: Nachemson A, Jonsson E, eds. Neck and Back Pain: The scientific evidence of causes, diagnosis and treatment. Philadelphia: Lippincott Williams \& Wilkins, 2000:2.xiii.

7. Noble M, Treadwell JR, Tregear SJ, et al. Long-term opioid management for chronic noncancer pain. Cochrane Database Syst Rev 2010(1):CD006605.

8. Deshpande A, Furlan A, Mailis-Gagnon A, Atlas S, Turk D. Opioids for chronic low-back pain. Cochrane Database Syst Rev 2007(3):CD004959.

9. Rossignol M, Arsenault B, Dionne C, et al. Clinic on Low-Back Pain in Interdisciplinary Practice (CLIP) guidelines. Montréal: Direction de santé publique, Agence de la santé et des services sociaux de Montréal, 2007.

10. Top Alberta Doctors. Management of Low Back Pain. [Alberta]: Toward Optimized Practice; 2009 <www.topalbertadoctors.org/cpgs/ back_pain.html> (Accessed November 20, 2009).

11. Chou R, Qaseem A, Snow V, et al. Diagnosis and treatment of low back pain: A joint clinical practice guideline from the American College of Physicians and the American Pain Society. Ann Intern Med 2007;147:478-91.

12. Canadian Guideline for Safe and Effective Use of Opioids for Chronic Non-Cancer Pain 2010 National Opioid Use Guideline Group (NOUGG). <http://nationalpaincentre.mcmaster.ca/ opioid/> (Accessed March, 2011)

13. Targin Product Monograph, Purdue Pharma, March 30, 2010.

14. Vondrackova D, Leyendecker P, Meissner W, et al. Analgesic efficacy and safety of oxycodone in combination with naloxone as prolonged release tablets in patients with moderate to severe chronic pain. J Pain 2008;9:114-54.

15. Simpson K, Leyendecker P, Hopp M, et al. Fixed-ratio combination oxycodone/naloxone compared with oxycodone alone for the relief of opioid-induced constipation in moderate-to-severe noncancer pain. Cur Med Res Opin 2008;24:3503-12.

16. Lowenstein O, Leyendecker P, Hopp M, et al. Combined prolongedrelease oxycodone and naloxone improves bowel function in patients receiving opioids for moderate-to-severe non-malignant chronic pain: A randomized controlled trial. Expert Opin Pharmacother 2009;10:531-43.

17. Sandner-Kiesling A, Leyendecker P, Hopp M, et al. Long-term efficacy and safety of combined prolonged-release oxycodone and naloxone in the management of non-cancer chronic pain. Int J Clin Pract 2010;64:763-74.

18. Schutter U, Grunert S, Meyer C, Schmidt T, Notle T. Innovative pain therapy with a fixed combination of prolonged-release oxycodone/naloxone: A large observational study under conditions of daily practice. Cur Med Res Opin 2010;26:1377-87.

19. Watson CP, Babul N. Efficacy of oxycodone in neuropathic pain: A randomized trial in postherpetic neuralgia. Neurology 1998;50:1837-41.

20. Watson CP, Moulin D, Watt-Watson J, et al. Controlled-release oxycodone relieves neuropathic pain: A randomized controlled trial in painful diabetic neuropathy. Pain 2003;105:71-8.

21. Beaulieu AD, Peloso P, Bensen W, et al. A randomized, doubleblind, 8-week crossover study of once-daily controlled-release tramadol versus immediate-release tramadol taken as needed for chronic noncancer pain. Clin Ther 2007;29:49-60.

22. Raffa RB, Friderichs E, Reimann W, Shank RP, Codd EE, Vaught JL. Opioid and nonopioid components independently contribute to the mechanism of action of tramadol, an "atypical" opioid analgesic. J Pharmacol Exp Ther 1992;260:275-85. 
23. Russell A, Watson CPN, Clark AJ, et al. Evaluation of dosing guidelines for use of controlled-release codeine in chronic noncancer pain. Pain Res Manage 2003;8:143-48.

24. Hagen NA, Thirlwell M, Eienhoffer J, Quigley P, Harsanyi Z, Darke A. Efficacy, safety and steady-state pharmacokinetics of once-a-day controlled-release morphine (MS Contin XL) in cancer pain. J Pain Symptom Manage 2005;29:80-90.

25. Arkinstall W, Sandler A, Goughnour B, et al. Efficacy of controlledrelease codeine in chronic non-malignant pain: A randomized placebo-controlled trial. Pain 1995;62:169-78.

26. Pollard CA. Preliminary validity study of the Pain Disability Index. Percept Mot Skills. 1984;59:974.

27. Tait RC, Chibnall JT, Krause S. The Pain Disability Index: Psychometric properties. Pain 1990;40:171-82.

28. Kopec JA, Esdaile JM, Abrahamowicz M, et al. The Quebec Back Pain Disability Scale. Measurement properties. Spine 1995;20:341-52.

29. Rentz AM, Yu R, Müller-Lissner S, Leyendecker P. Validation of the Bowel Function Index to detect clinically meaningful changes in opioid-induced constipation. J Med Econ 2009;12:371-83.

30. Brazier JE, Harper R, Jones NM, et al. Validating the SF-36 health survey questionnaire: New outcome measure for primary care. BMJ 1992;305:160-4.

31. Bronfort G, Bouter LM. Responsiveness of general health status in chronic low back pain: A comparison of the COOP charts and the SF-36. Pain 1999;83:201-9.

32. Sibley J, Kelly A, Rashiq S, et al. Controlled release oxycodone and acetaminophen plus codeine in chronic low back pain. [Abstract]. 10th World Congress on Pain, San Diego, August 17 to 22, 2002:429.

33. Hurst $\mathrm{H}$, Bolton J. Assessing the clinical significance of change scores recorded on subjective outcome measures. J Manipulative Physio Ther 2004;27:26-35.

34. Handelsman L, Cochrane KJ, Aronson MJ, Ness R, Rubinstein KJK, Kanoff PD. Two new rating scales for opiate withdrawal. Am J Drug Alcohol Abuse 1987;13:293-308.

35. Elkader AK, Brands B, Callaghan R, Sproule BA. Exploring the relationship between perceived inter-dose opioid withdrawal and patient characteristics in methadone maintenance treatment. Drug Alcohol Depend 2009;105:209-14.

36. Jones B, Kenward MG. Design and Analysis of Cross-Over Trials, 2nd edn. Boca Raton: Chapman \& Hall/CRC, 2003.

37. Dworkin R, Turk D, Wyrwich $\mathrm{K}$, et al. Interpreting the clinical importance of treatment outcomes in chronic pain clinical trials: IMMPACT recommendations. J Pain 2008;9:105-21.

38. Mystakidou K, Clark AJ, Fischer J, Lam A, Pappert K, Richarz U. Treatment of chronic pain by long-acting opioids and the effects on sleep. Pain Pract 2011;11:282-9
39. Edwards RR, Almeida DM, Klick B, Haythornthwaite JA, Smith MT. Duration of sleep contributes to next-day pain report in the general population. Pain 2008;137:202-7.

40. Gimbel JS, Richards P, Portenoy RK. Controlled-release oxycodone for pain in diabetic neuropathy: A randomized controlled trial. Neurology 2003;60:894-5.

41. Attal N, Guirimand F, Brasseur L, et al. Effects of IV morphine in central pain: A randomized placebo-controlled study. Neurology 2002;58:554-63.

42. Rowbotham MC, Twilling L, Davies PS, et al. Oral opioid therapy for chronic peripheral and central neuropathic pain. N Engl J Med 2003;348:1223-32.

43. OxyContin Product Monograph, August 25, 2009.

44. Martell BA, O'Connor PG, Kems RD, et al. Systematic review: Opioid treatment for chronic back pain: Prevalence, efficacy, and association with addiction. Ann Int Med 2007;146:116-27.

45. Jamison RN, Raymond SA, Slawsby EA, et al. Opioid therapy for chronic noncancer back pain: A randomized prospective study. Spine 1998;23:2591-600.

46. Simpson RK Jr, Edmondson EA, Constant CF, Collier C. Transdermal fentanyl as treatment for chronic low back pain. J Pain Symptom Manage 1997;14:218-24.

47. Muller FO, Odendaal CL, Muller FR, et al. Comparison of the efficacy and tolerability of a paracetamol/codeine fixed-dose combination with tramadol in patients with refractory chronic back pain. Arzneimittelforschung 1998;48:675-9.

48. Hale ME, Fleischmann R, Salzman R, et al. Efficacy and safety of controlled-release versus immediate-release oxycodone: Randomized, double-blind evaluation in patients with chronic back pain. Clin J Pain 1999;15:179-83.

49. Richards P, Zhang P, Friedman M, et al. Controlled release oxycodone releives moderate to severe pain in a 3-month study of persistent moderate to severe back pain. Pain Med 2002;3:176.

50. Portenoy RK, Farrar JT, Backonja M-M, et al. Long-term use of controlled-release oxycodone for non-cancer pain: Results of a 3-year registry study. Clin J Pain. 2007;23:287-99.

51. Hildebrandt J, Lindena $\mathrm{G}$, Maier $\mathrm{CH}$, et al. Long-term treatment with sustained release morphine in non-malignant pain (LAMONTAS). 9th World Congress of Pain, Vienna, August 22 to 27, 1999.

52. Gordon DN, Broughton AN, Miller AJ. Long term efficacy of CR oxycodone (OxyContin tablets) in 101 patients treated for 12 months. 9th World Congress of Pain, Vienna, August 22 to 27, 1999. 


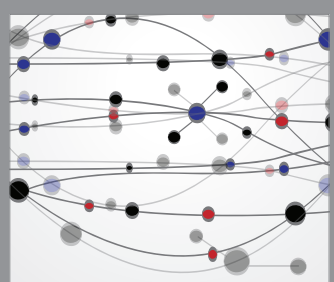

The Scientific World Journal
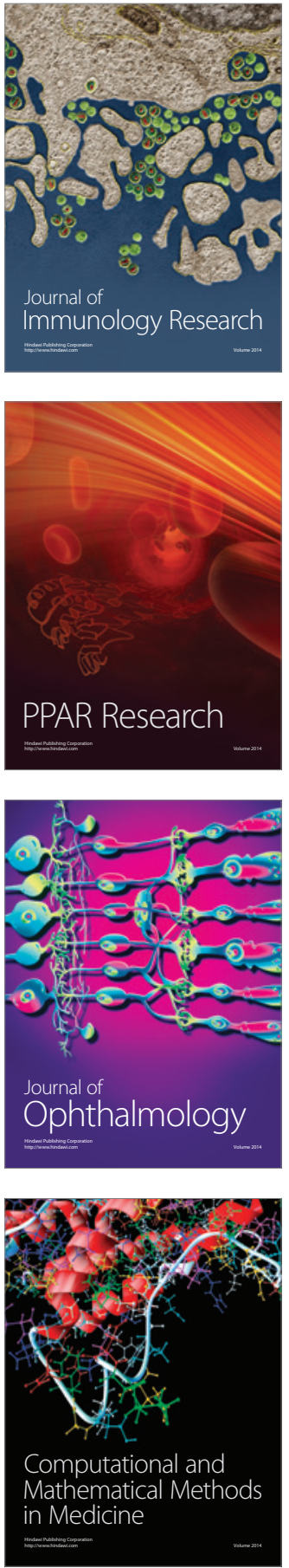



Gastroenterology Research and Practice

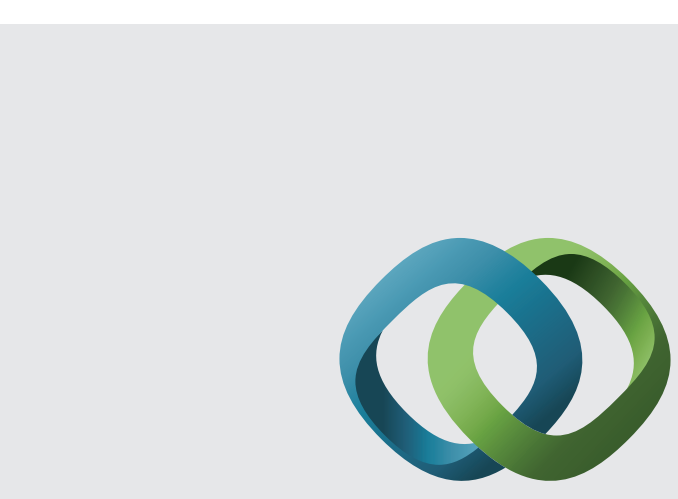

\section{Hindawi}

Submit your manuscripts at

http://www.hindawi.com
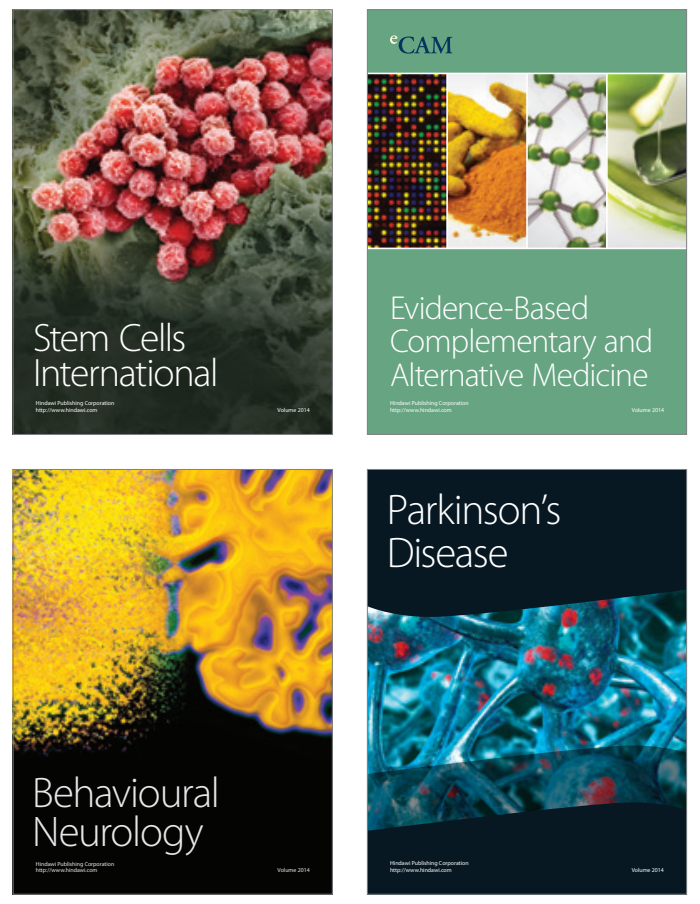
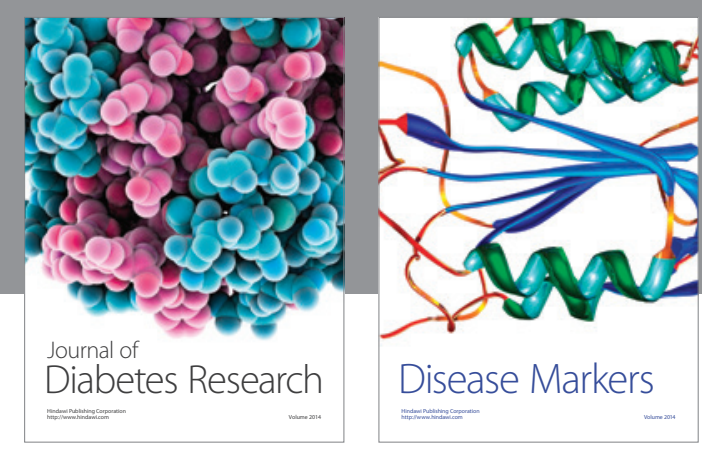

Disease Markers
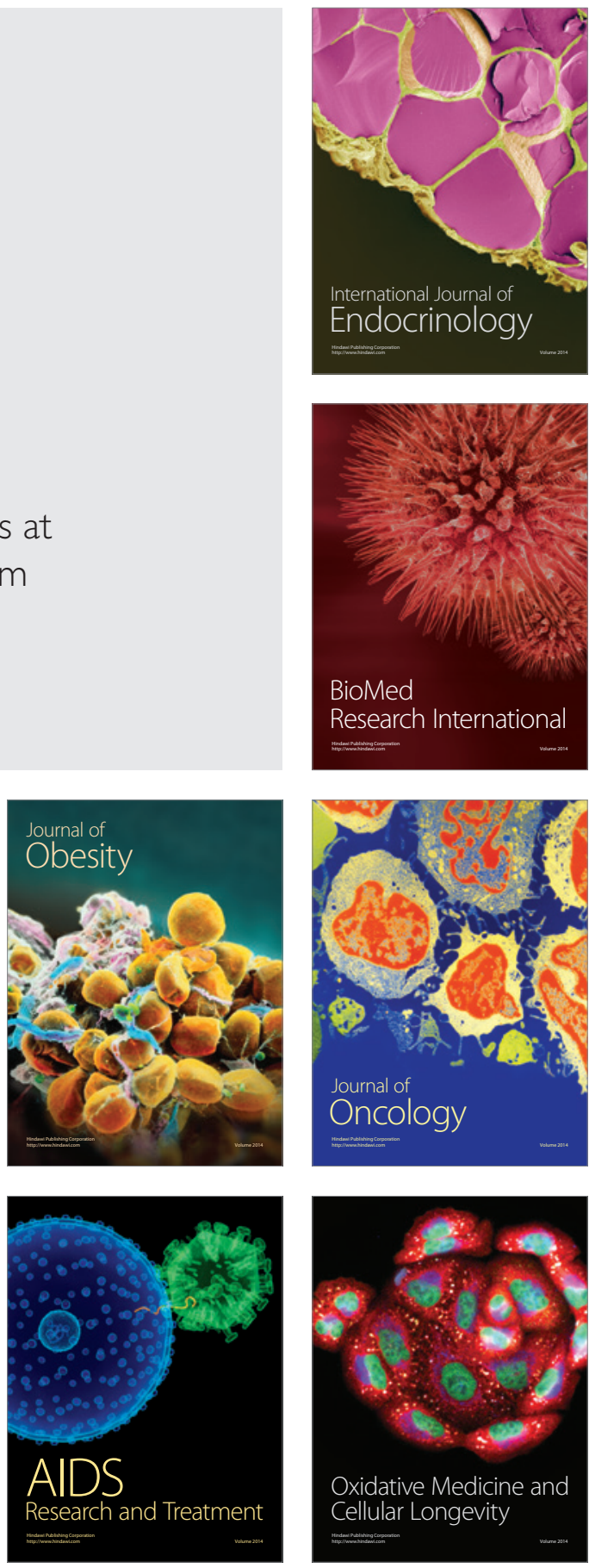